Research Article

\title{
The Mechanism of Rock Mass Crack Propagation of Principal Stress Rotation in the Process of Tunnel Excavation
}

\author{
Guanfeng Chang $\mathbb{D},{ }^{1}$ Xinzhu Hua, ${ }^{1}$ Jie Zhang $\mathbb{D}^{2}$ and Peng $\mathrm{Li}^{3}$ \\ ${ }^{1}$ State Key Laboratory of Mining Response and Disaster Prevention and Control in Deep Coal Mines, \\ Anhui University of Science and Technology, Huainan 232001, Anhui, China \\ ${ }^{2}$ School of Civil and Resource Engineering, University of Science and Technology Beijing, Beijing 100018, China \\ ${ }^{3}$ School of Mines, China University of Mining and Technology, Xuzhou 221116, China \\ Correspondence should be addressed to Jie Zhang; ah20102010@163.com
}

Received 17 June 2021; Accepted 7 August 2021; Published 14 August 2021

Academic Editor: Guanglei Zhang

Copyright (c) 2021 Guanfeng Chang et al. This is an open access article distributed under the Creative Commons Attribution License, which permits unrestricted use, distribution, and reproduction in any medium, provided the original work is properly cited.

\begin{abstract}
Rock excavation has experienced complex stress paths. The development of the original crack under the path of principal stress magnitude and principal stress direction is a key scientific problem that needs to be solved in rock underground engineering. The principal stress magnitude dominates the initiation and propagation of the crack and increases rock damage under the action of principal stress rotation. In this study, the theoretical calculation and numerical analysis method have been combined with the crack propagation conditions to study the stress-driven mechanism of brittle rock crack propagation under principal stress rotation. The results show that the "relative initial angle" of crack angle is being updated in time during the principal stress rotation process; once the stress is rotated, it will become the next initial crack angle; the crack propagation direction is deviated under the applied shear load, and it is always in the direction of minimum shear load, leading to a certain degree of inhibition of crack propagation depth in the initial direction. According to the results of numerical simulation, the effect of principal stress rotation caused by mining excavation is obvious and has a certain range of influence depth, the stress of surrounding rock of roadway is the highest within the depth range of $1 \sim 2 \mathrm{~m}$, and the maximum principal stress is as high as $26.89 \mathrm{MPa}$. The rotation of principal stress direction on the roadway surrounding rock surface is the strongest, which makes the surrounding rock more fragmented, and the middle principal stress and the maximum principal stress rotate about $90^{\circ}$ counterclockwise along the Ox axis. Studying the action mechanism of principal stress rotation on fractured rock masses can provide scientific basis for geotechnical engineering design and rock mass surrounding support.
\end{abstract}

\section{Introduction}

Fractured rock mass is the main occurrence form of rock mass in nature, its strength and deformation failure are significantly affected by the generation and expansion of cracks, and the mechanical behavior of rock mass changes with the change of stress paths [1-3]. Because of the influence of engineering disturbance, in situ stress state changes not only the stress magnitude, but also the rotation of the principal stress direction, which is an important factor in the research of inducing rock mass stress concentration and rock strength degradation. The excavation of rock mass in underground engineering can cause the surrounding rock stress in the excavation direction, resulting in the stress state of the fracture surface changing from the compressive shear stress state to the tensile shear stress state. Based on the theory of fracture mechanics, crack propagation generally shows strong tensile characteristics, and the unloading failure of rock bridge is dominated by tensile shear composite failure $[4,5]$. Accordingly, fractures are more easily expanded under tensile shear stress. During a mining excavation, the principal stress level and the principal stress direction change; in other words, the changes in stress state of surrounding rock at any time lead to a certain range of damage to the rock mass on the excavation face $[6,7]$, 
which will also have significant impacts on the expansion of rock mass cracks and deformation and failure of surrounding rock $[8,9]$.

The expansion and the distribution of unloading cracks are the basis for the study of rock mass failure and surrounding rock stability in underground engineering. At present, crack propagation and damage mechanism of rock bridges are studied under compression and shear stress. Li and Qi [10], based on the microcrack growth-induced stressstrain constitutive relationship, the relationship between quasistatic and dynamic fracture toughness, the relationship between crack velocity and strain rate, and the relationship between strain rate and dynamic fracture toughness, proposed a micromechanics-based stress-strain constitutive model. Li et al. [11] studied the effect of the angle of flaws at the end surface on the dynamic properties of and crack propagation in rock, and cylindrical marble specimens of $50 \mathrm{~mm} \times 50 \mathrm{~mm}$ were manufactured with flaws of different angles. A series of impact loading tests were carried out with a system of split Hopkinson pressure bar (SHPB) with the diameter of $50 \mathrm{~mm}$. The crack propagation and dynamic failure processes were recorded real-timely by a high speed camera. Sun et al. [12] investigated the influence of the fissure morphology on the dynamic mechanical properties of the rock and the crack propagation, and a drop hammer impact test device was used to conduct impact failure tests on sandstones with different fissure numbers and fissure dips, simultaneously recording the crack growth after each impact. The box fractal dimension is used to quantitatively analyze the dynamic change in the sandstone cracks, and a fractal model of crack growth over time is established based on fractal theory. Pan et al. [13], in order to study the influence of the size distribution and preferred orientation of mineral grains, proposed a statistical grain-based discrete element method coupling with the cohesive zone model on the basis of the universal distinct element code (UDEC) in this study, and the strength characteristics, deformation response, and failure mode of rocks were numerically examined using the proposed model by varying the size distribution and preferred orientation of mineral grains. Fu et al. [14] studied the failure process of double cracked rock specimens under uniaxial and two-dimensional compression by FLAC3D numerical simulation software. Shang et al. [15], based on the three-dimensional numerical simulation, simulated a rock uniaxial compression test by FLAC3D. Meng et al. [16], based on FLAC3D numerical analysis, discussed the distribution characteristics of stress concentration, fracture expansion, and time-dependent deformation of the surrounding rock of the cavern groups, and the formation mechanism of deep deformation is explained. Wang et al. [17] studied the instability failure behaviors, acoustic emission (AE) characteristics, and damage evolution rules of green sandstone caverns with different joint angles. First, the influences of joint angles on the strength and failure behavior of the caverns were analyzed. Then, the $\mathrm{AE}$ characteristics and damage evolution rules of jointed caverns in the process of failure were discussed. Zhou et al. [18] used friction sliding crack model to study the microcrack damage mechanism of brittle rock under rotation of the principal stress axes, and through the uniaxial compression test of preexisting cross-embedded cracks, the main difference between $2 \mathrm{D}$ and $3 \mathrm{D}$ cracking behavior of preexisting cracks is discussed, and the further propagation of extended wing crack leads to the ultimate failure of the specimen. Liu et al. [19], in order to obtain the mechanism of crack propagation of oriented perforation hydraulic fracture and its effect on mechanical properties of rock samples, carried out an experimental study on hydraulic fracture of rock samples without confining pressure. The confining pressure ratio coefficient was defined, and oriented perforation hydraulic fracture was numerically simulated based on the extended finite element method so as to explore the comprehensive influence of different perforation parameters. Wang et al. [20], so as to improve surrounding rock control in such longwall face, investigated the mining induced stress rotation and its influence on surrounding rock stability with theoretical analysis, numerical simulation, and field measurement. Wu et al. [21] carried out a series of impact loading tests on sandstone samples with and without a circular cavity by a modified split Hopkinson pressure bar (SHPB) test system, the mechanical properties and energy evolution of the samples were systematically investigated, and the effect of cavity size was analyzed. Li et al. [22] used FLAC3D to analyze the stress path and the failure mode of surrounding rock in mining processes of the Mine-by test hole and found that the rotation of stress principal axis would aggravate the damage of surrounding rock when the rock crack reaches the initiation stress threshold. Hoek et al. [23] analyzed the fracture initiation and propagation in intact rock under biaxial compressive stress and found that a large number of tension cracks near the boundary of the cavern were caused by the existence of microcracks in the rock mass. Tension cracks begin at the tip of the initial crack and further expand, and their propagation and length are controlled by the principal stress ratio.

Under excavation unloading conditions, the rotation of the principal stress changes the stress ratio, leading to tension failure under low stress ratio conditions. Tension cracks are restrained when the stress ratio reaches a certain level, and the failure mode of surrounding rock begins to transition to shear failure. The change of tunnel stress state is different from single compression-shear stress and tensionshear stress. On the basis of previous studies, the plane and nonplane propagation mechanisms of cracks are theoretically analyzed, and the evolution law of surrounding rock stress and the evolution characteristics of surrounding rock plastic zone during tunnel excavation are analyzed by numerical simulation.

\section{Mechanical Analysis of Crack Development}

Underground rock excavation can be approximated as a plane strain problem. It is assumed that the surrounding rock is not deformed or negligible in the direction of the parallel tunnel axis, and the rock mass is dominated by type I fractures (stretched or open type) and type II fractures (shear-slip type) under unloading conditions, i.e., I-II composite fractures. For I-II composite plane problems, the stress field at the crack tip 
can be obtained by solutions of the type I and type II [24]. In order to facilitate the analysis, the actual curvilinear wing crack can be approximated by a straight open crack growing parallel to the direction of the principal compressive stress, ignoring the nonsingular phase. The stress components near the crack tip are shown in Figure 1 and can be expressed in polar coordinates as

$$
\left.\begin{array}{l}
\sigma_{r}=\frac{1}{2(2 \pi r)^{1 / 2}}\left[K_{I}\left(3-\cos \theta \cos \frac{\theta}{2}\right)+K_{I I}(3 \cos \theta-1) \sin \frac{\theta}{2}\right] \\
\sigma_{\theta}=\frac{1}{2(2 \pi r)^{1 / 2}} \cos \frac{\theta}{2}\left[K_{I}(1+\cos \theta)-3 K_{I I} \sin \theta\right] \\
\sigma_{r, \theta}=\frac{1}{2(2 \pi r)^{1 / 2}} \cos \frac{\theta}{2}\left[K_{I} \sin \theta+K_{I I}(3 \cos \theta-1)\right]
\end{array}\right\}
$$

According to the theory of maximum hoop tensile stress [25], a crack is initiated when $\left(\sigma_{\theta}\right)_{\max }$ reaches the critical value $\sigma_{C}$. In order to find the maximum direction angle of $\sigma_{\theta}$, $\sigma_{\theta}$ is derived for $\theta$, and then equation (2) is derived according to the second formula in equation (1):

$$
\frac{\partial \sigma_{\theta}}{\partial_{\theta}}=0
$$

That is,

$$
K_{I} \sin \theta+K_{I I}(3 \cos \theta-1)=0 .
$$

The following equation can be obtained:

$$
2 K_{I I} \tan ^{2} \frac{\theta}{2}-K_{I} \tan \frac{\theta}{2}-K_{I I}=0 .
$$

where $\lambda=\left(K_{I I} / K_{I}\right)$, and the solution of $\tan (\theta / 2)$ in equation (4) can be derived as

$$
\tan \frac{\theta_{0}}{2}=\frac{1+\left(1+8 \lambda^{2}\right)^{1 / 2}}{4 \lambda} .
$$

When $K_{I I}$ is positive and $\theta_{0}$ is negative, then $\theta_{0}$ can be described as

$$
\theta_{0}=2 \arctan \frac{1-\left(1+8 \lambda^{2}\right)^{1 / 2}}{4 \lambda} .
$$

Equation (6) shows that the crack will expand toward original fracture surface in the direction of $\theta_{0}$ angle under the I-II composite load, and the sign of the $\theta_{0}$ angle depends on the sign of $K_{I I}$. When $K_{I I}$ is a positive sign, $\theta_{0}$ will be a negative value, and vice versa.

After determining the splitting angle $\theta_{0}, \sigma_{C}$ can be obtained from the cracking load condition. Substituting $\theta=$ $\theta_{0}$ into the formula (1) yields the expression for $\sigma_{\theta}$, which equates to $\sigma_{C}$.

$$
\left(\sigma_{\theta}\right)_{\max }=\frac{1}{2(2 \pi r)^{1 / 2}} \cos \frac{\theta_{0}}{2}\left[K_{I}\left(1+\cos \theta_{0}\right)-2 K_{I I} \sin \theta_{0}\right]=\sigma_{C} .
$$

According to the theory of maximum hoop tensile stress, pure I-type cracks are a special case of composite cracks, and formula (7) must be applied to pure type I. At this time, $K_{I I}=0$, $\theta_{0}=0$, so $\left(\sigma_{\theta}\right)_{\max }$ can be described as

$$
\left(\sigma_{\theta}\right)_{\max }=\frac{K_{I}}{(2 \pi r)^{1 / 2}}=\sigma_{C}=\frac{K_{I C}}{(2 \pi r)^{1 / 2}} .
$$

Substituting equation (8) into equation (7), a composite fracture criterion can be obtained:

$$
\frac{1}{2} \cos \frac{\theta_{0}}{2}\left[K_{I}\left(1+\cos \theta_{0}\right)-3 K_{I I} \sin \theta_{0}\right]=K_{I C} .
$$

From equations (6) and (9), the envelopes of $K_{I}$ and $K_{I I}$ can be obtained, which satisfy the complex fracture criterion. At the point outside the envelopes, brittle fracture will occur.

\section{Plane Problem Study}

3.1. Uniaxial Compression and Tension Problems. Under the action of excavation unloading, the stress state of surrounding rock gradually changes from compression to tension. Taking the plane plate with inclined crack as an example, the stress intensity factor of rock mass under uniaxial compression load and uniaxial tension load is analyzed, as shown in Figures 2 and 3. The crack length is $2 a$, and the angle between the stress axis is $\beta$, the compressive stress is $\sigma_{c}$, the tensile stress is $\sigma$, the effective shear stress is expressed by $\tau_{\mathrm{e}}$ [24], and then the stress intensity factors of type I and type II under compressive stress are given, respectively:

$$
\left.\begin{array}{c}
K_{I}=\frac{2 a \tau_{e} \cos \beta}{\sqrt{\pi a}} \\
K_{I I}=-\frac{2 a \tau_{e} \sin \beta}{\sqrt{\pi a}}
\end{array}\right\} .
$$

Type I and type II stress intensity factors under tensile stress state are, respectively,

$$
\left.\begin{array}{l}
K_{I}=\sigma \sqrt{\pi a} \sin ^{2} \beta \\
K_{I I}=\sigma \sqrt{\pi a} \sin \beta \cos \beta
\end{array}\right\} .
$$

The relationship between the fracture angle $\theta_{0}$ and the crack angle $\beta$ can be obtained by substituting equations (10) and (11) into formula (3).

$$
\begin{aligned}
& \sin \theta_{0}+\left(3 \cos \theta_{0}-1\right) \cot \beta=0, \\
& \sin \theta_{0}+\left(3 \cos \theta_{0}-1\right) \tan \beta=0 .
\end{aligned}
$$

Under uniaxial compression, the corresponding fracture angle $\theta_{0}$ can be obtained by bringing the given crack angle $\beta$ into formula (6), as shown in Figure 3. When $\beta=0$, $\theta_{0}=\arccos (1)=0^{\circ}$, the fracture angle of crack growth increases with the increase of crack angle, and the crack growth direction is approximately consistent with the maximum compressive stress direction. In the uniaxial tension state, if $0<\beta<(\pi / 2), \theta_{0}<0$; if $\beta=0,-\theta_{0}=\arccos (1 / 3) \approx 70.5$. It can be seen that as the crack angle $\beta$ increases, the fracture angle $\theta_{0}$ of crack development decreases. This indicates that the crack 


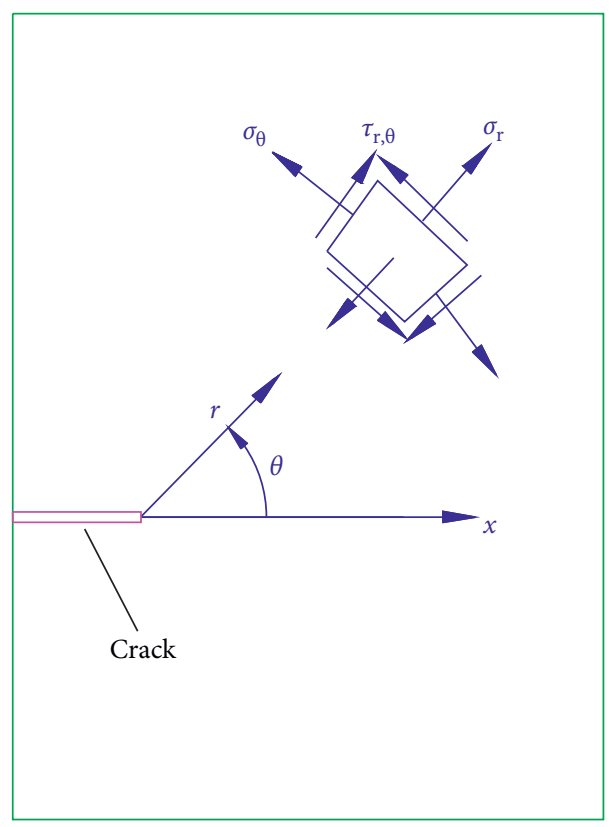

FIGURE 1: The polar component of the crack tip stress.

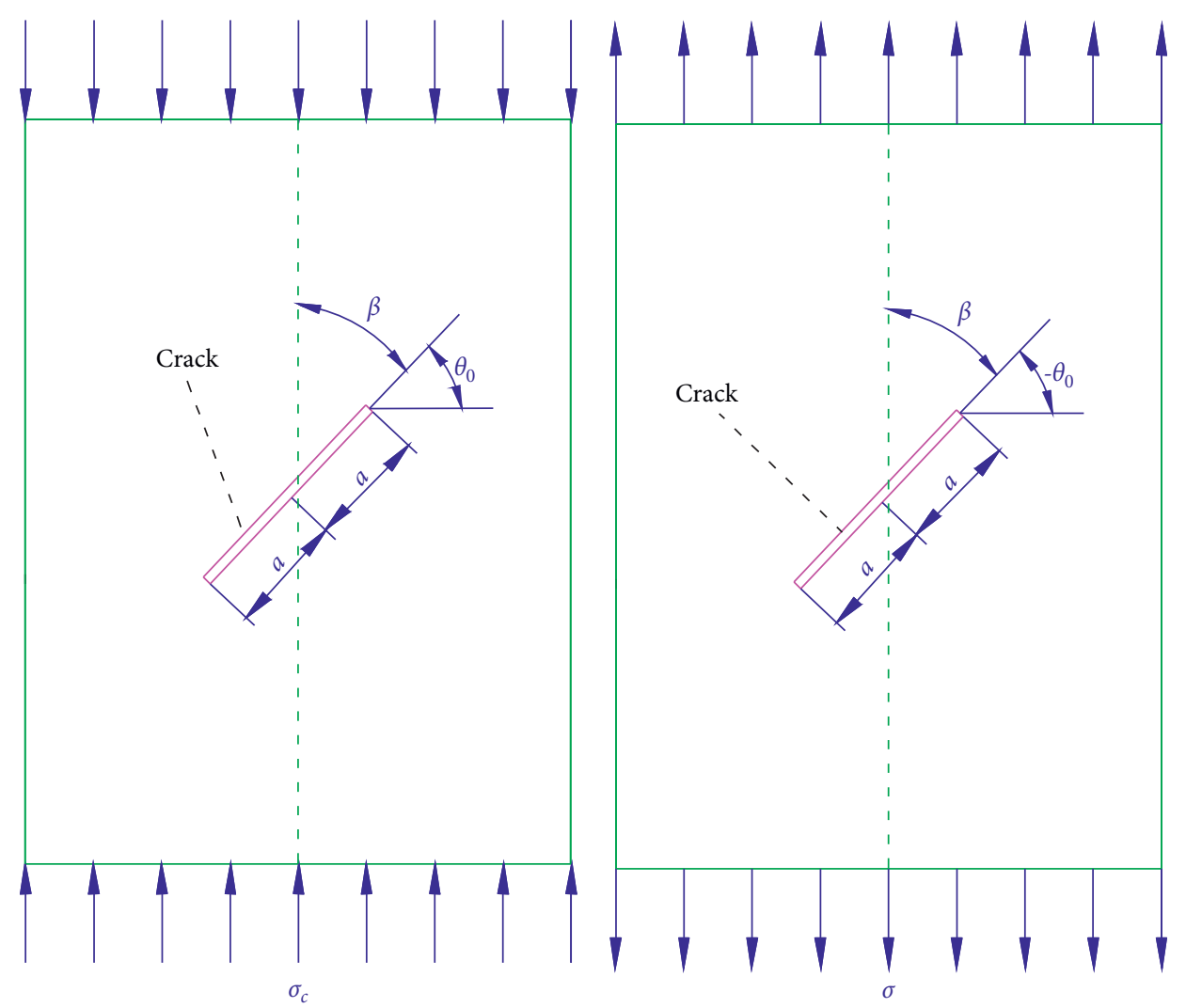

(a)

(b)

FIgURE 2: Unidirectional cracked plate model. (a) Compression crack. (b) Tension crack. 


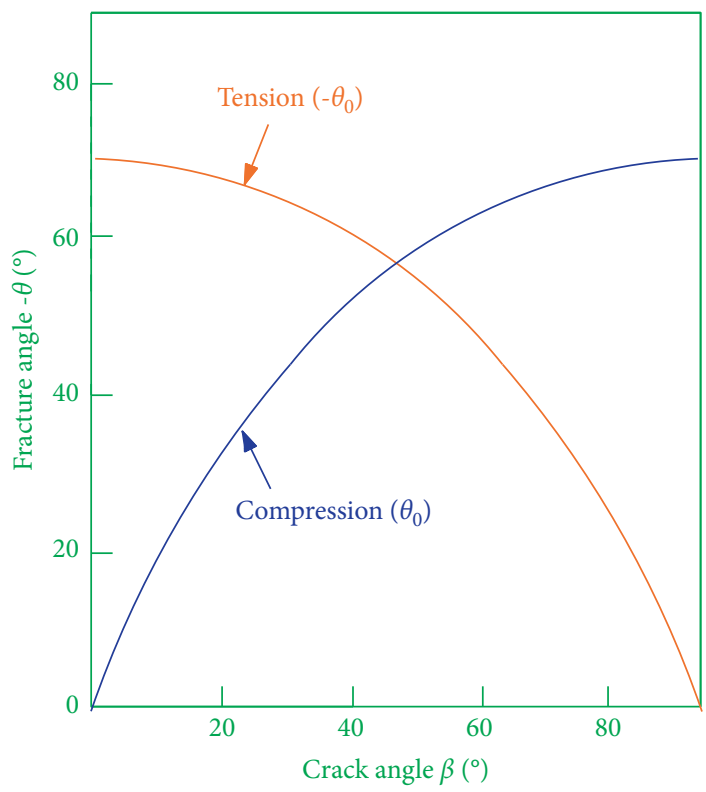

FIGURE 3: Relationship between fracture angle and crack angle.

propagation direction is consistent with the direction of maximum hoop tensile stress $\sigma_{\theta}$ under the oblique tensile stress. It can be seen from formulae (11) and (12) that the fracture angle $\theta_{0}$ is only related to the crack angle $\beta$ and is independent of the material elastic modulus $E$ and Poisson's ratio $\nu$.

3.2. Nonplanar Crack Expansion Problem. In the two-dimensional plane, the crack propagates along the maximum tensile stress component in the plane, and the crack is likely to deviate from its original plane due to the influence of shear load. When the crack begins to propagate away from its own plane, the nonplanar propagation of the crack is constructed into a complex model [26], as shown in Figure 4.

The direction of the maximum tensile stress component is set in the direction of the incremental expansion $\mathrm{d} c$. Only the I-II composite fracture condition is considered: the crack plane has a rotation with the angle $\theta$ around the $O Z$ axis. When the crack plane is twisted around the $O X$ axis by an angle $\varphi$, it is a case of I-III composite type crack, which will not be discussed. The stress acting on the imaginary crack extension surface is obtained according to formula (1) by an appropriate tensor transformation.

Under the rotation of the angle $\theta$, the relevant normal stress component and shear stress component on the new plane [27] are

$$
\left.\begin{array}{l}
\sigma_{y^{\prime} y^{\prime}}=\frac{1}{(2 \pi r)^{1 / 2}}\left(K_{I} f_{\theta \theta}^{I}+K_{I I} f_{\theta \theta}^{I I}\right) \\
\sigma_{x^{\prime} y^{\prime}}=\frac{1}{(2 \pi r)^{1 / 2}}\left(K_{I} f_{r \theta}^{I}+K_{I I} f_{r \theta}^{I I}\right) \\
\sigma_{x^{\prime} z^{\prime}}=0
\end{array}\right\},
$$

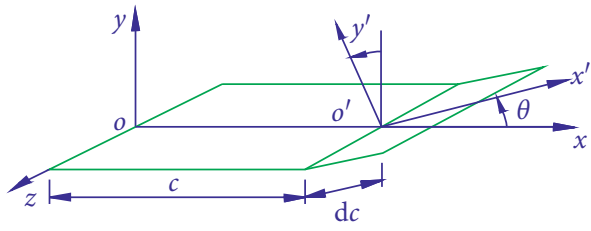

FIGURE 4: Nonplanar extended model of inclined crack.

where $f_{i j}^{I}$ and $f_{i j}^{I I}$ terms in the formulas can be directly obtained from formula (1).

It can be seen from equation (14) that the corresponding stress component takes the maximum value when $\beta=0$ is used, indicating that the crack propagation tends to spread along its own plane. On the other hand, the applied shear stress causes the crack to deviate from the original plane, when the inclined crack propagates, and the crack always occurs in the direction of the minimum shear load. Therefore, it can be considered that the shear stress is a correction, and its function is to return the deflected crack to a stable plane, which is perpendicular to the maximum principal tensile stress caused by the applied field.

In the case of I-II composite cracks, the crack propagates away from the near-field region of the crack and enters the far field of the applied load. The crack system's grooming load gradually changes from mixed to pure I, which tends to unidirectional tensile failure of the crack. Figure 5 is a process model, in which a slanted defect develops to an actual crack [24]. The arrow shows the various load components acting on the preexisting crack $S S^{\prime}$. As the crack expands further, the I-type load is much larger than the IItype load.

The cracks originate from defects in rock and continue to spread on a relatively smooth surface, and the crack tip will always bear strong tensile stress, thus activating microcracks in 


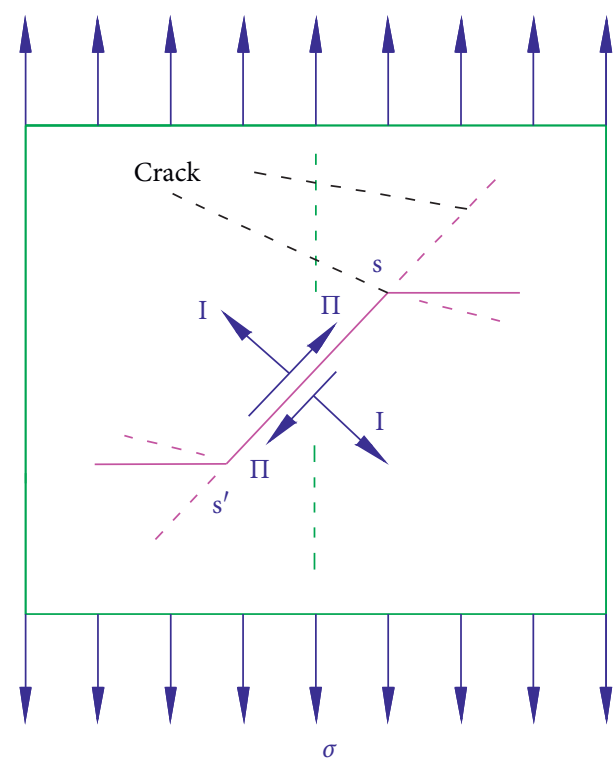

Figure 5: Crack propagation in a flat plate with uniform tensile stress.

the crack tip area [28]. With the rotation of stress direction, the microscopic crack path instability eventually leads to crack curving and branching, and coarser fracture plane. During the development of rough surface, the crack propagation becomes unstable, and the secondary crack deviates [29]. For the initial expansion, the direction of the defect is indeed a very important fracture mechanics parameter, and when the cracks extend beyond the influence area of defects, the influence of the direction of defects weakens due to the deviation of secondary cracks.

The secondary fracture originates from the front of the extended crack tip and develops backwards to connect with the main fracture tip. And the microcracks begin to spread and then are absorbed by the leading edge of the main crack in front of the crack front edge. As crack accelerates, the main crack field strengthens, and the microcracks further form in front of the main crack and develop into a separate entity.

\section{Numerical Model Analysis}

4.1. Model Establishment. According to the theory of elastic mechanics, the directions of the underground excavation body, including the tunnel and the stope, are preferably consistent with the direction of the maximum principal stress. Under these conditions, the stresses acting on the vertical section of the tunnel and the stope are relatively small principal stresses, which are favorable for their stabilities. Taking the geological conditions of Sanshandao mining area as an example, a numerical analysis model is established to study the variation characteristics of the principal stress magnitude and the rotation characteristics of principal stress direction of the surrounding rock with the excavation process. The rock mass of the model roadway is mainly granite, and its physical and mechanical parameters are shown in Table 1.
In this model, the surrounding rock is assumed to be an ideal elastoplastic material, and the Mohr-Coulomb criterion is adopted. The model defines the direction of tensile stress is positive, and the direction of compressive stress is negative.

In order to reduce the influence of boundary conditions on the simulation results, the distance between the surrounding boundary and the center of the tunnel is set as nearly 5 times the width of it. The model of the horizontal direction of the $X$ axis is $40 \mathrm{~m}$ long, $40 \mathrm{~m}$ high in vertical direction, and $20 \mathrm{~m}$ long in $Y$ axis direction. Roadway size is width $\times$ height $=2.6 \mathrm{~m} \times 2.7 \mathrm{~m}$, left and right side walls have two cracks with crack angles $\beta=90^{\circ}$ and $0^{\circ}$, and the crack size is length $\times$ width $\times$ height $=1 \mathrm{~m} \times 0.025 \mathrm{~m} \times 0.5 \mathrm{~m}$. There are 373,082 mesh elements and 64,829 nodes in the model, and the numerical calculation model is shown in Figure 6. The roadway is excavated in 10 steps separately, and the excavation footage of each step is $2 \mathrm{~m}$. During the excavation process, the stress and displacement change information of vault and side wall of roadway cross section is recorded, which are monitoring point 1 and monitoring point 2 , respectively. According to the measured stress in the mining area, the vertical load on the upper boundary of the model is about 10.0 MPa. Meanwhile, the maximum horizontal principal stress is $20.0 \mathrm{MPa}$ ( $y$-axis direction), and the minimum horizontal principal stress is $7.0 \mathrm{MPa}$ ( $x$-axis direction).

4.2. Changes of Stress State of Surrounding Rock. In the initial stress state, the principal stress direction is the principal stress loading direction of the initial model. The roadway adopts full-face excavation, and the principal stress distribution after excavation is shown in Figure 7. It can be seen that the principal stress rotation is obvious in the range of $2.5 \sim 3 \mathrm{~m}$ depth at the top and bottom of the roadway and $1.5 \sim 2 \mathrm{~m}$ depth at the side wall of the roadway; With the change of stress direction, the magnitude of principal stress also changes. The stress of surrounding rock of roadway is the highest within the depth range of $1 \sim 2 \mathrm{~m}$, and the maximum principal stress is as high as $26.89 \mathrm{MPa}$. The stress nephogram is shown in Figure 8.

With the gradual process of mining excavation, the variation regulation of principal stress at model monitoring points is shown in Figure 9, in which the dots and short lines on the curve represent the direction of the principal stress. From the figure, it can be seen that, on the top and side walls, the tunnel excavation causes a degree of stress release and the rotation of the principal stress direction. With the advance of excavation, the minimum principal stress at the top of tunnel gradually rotates from the initial horizontal direction to the initial intermediate principal stress direction, and the intermediate principal stress rotates to the initial direction of the maximum principal stress; meanwhile, the maximum principal stress rotates from the parallel tunnel axis direction to the initial minimum principal stress direction. At the same time, the minimum principal stress direction of the monitoring point of the side wall hardly rotates, while the middle principal stress and the maximum 
TABle 1: Physical and mechanical parameters of rock mass.

\begin{tabular}{lccccc}
\hline $\begin{array}{l}\text { Density of rock mass } \\
\rho\left(\mathrm{kg} \cdot \mathrm{m}^{-3}\right)\end{array}$ & $\begin{array}{c}\text { Modulus of elasticity } \\
E(\mathrm{GPa})\end{array}$ & $\begin{array}{c}\text { Internal friction } \\
\text { angle } \varphi\left(^{\circ}\right)\end{array}$ & $\begin{array}{c}\text { Cohesion } \\
c(\mathrm{MPa})\end{array}$ & $\begin{array}{c}\text { Poisson } \\
\text { ratio } \mu\end{array}$ & $\begin{array}{c}\text { Tensile strength } \\
\sigma_{t}(\mathrm{MPa})\end{array}$ \\
\hline 2700.0 & 8.0 & 36.0 & 0.7 & 0.2 & 0.5 \\
\hline
\end{tabular}

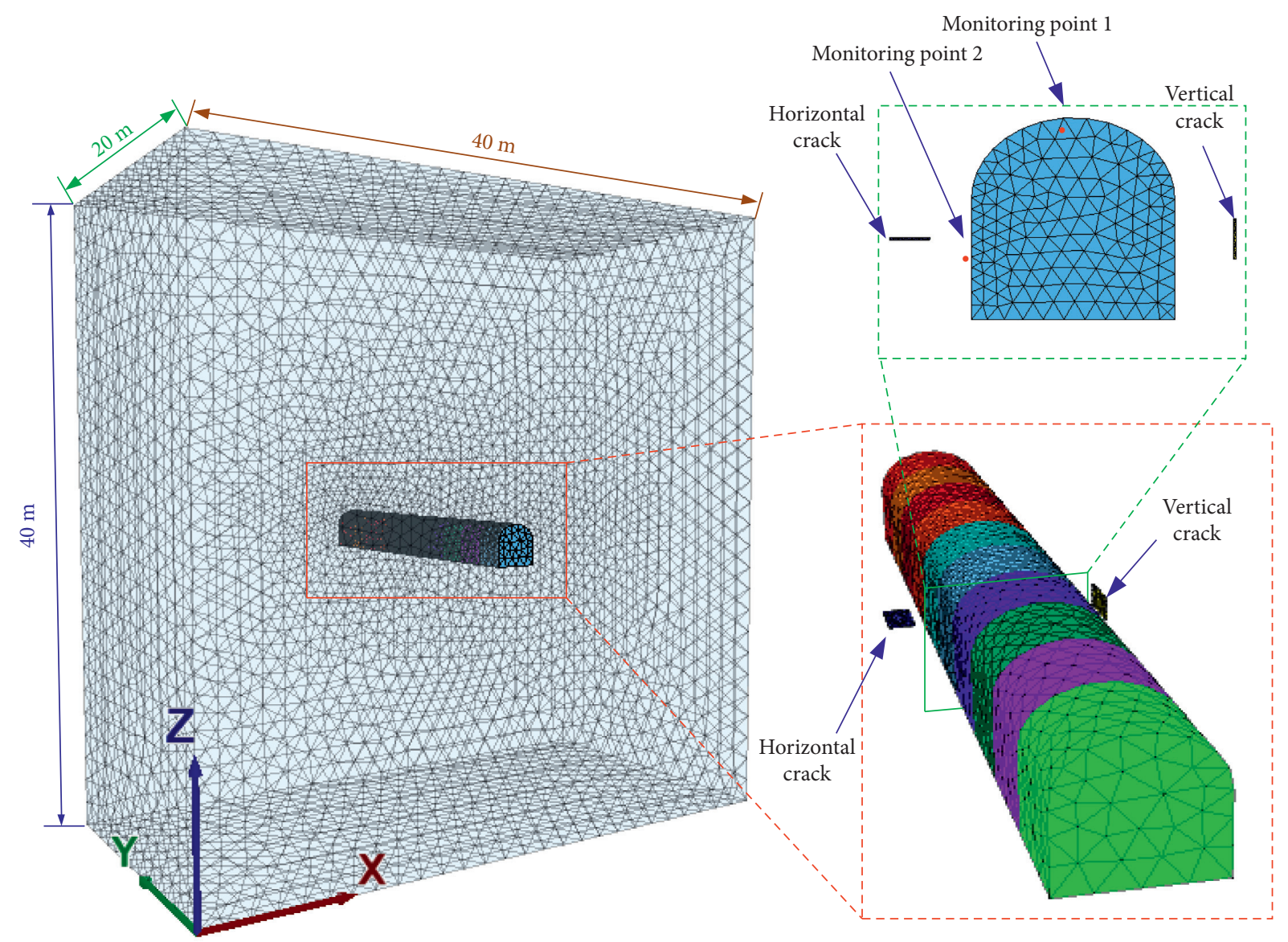

Figure 6: Numerical calculation model.

principal stress rotate about $90^{\circ}$ counterclockwise along the $0 x$ axis. The adjustments of principal stress directions of surrounding rock on the top and side walls of tunnel show that the plane of maximum and minimum principal stresses is parallel to the mining excavation face, while the direction of intermediate principal stress is perpendicular to the excavation face. The magnitude and direction of the principal stress of surrounding rock at the monitoring points change strongly in the next step of excavation; that is, the change lags behind the excavation face.

4.3. Law of Plastic Zone Expansion of Surrounding Rock. After excavation, the distribution of plastic zone in the surrounding rock of roadway is shown in Figure 10. It can be seen from Figure 7 that the principal stress direction of surrounding rock on the roadway surface is basically parallel to the contour line of roadway section, and the plastic zone in this area is mainly shear plastic zone. There is a local tensile plastic zone in the middle of the roadway floor, which shows that the floor bulges and the upward displacement reach $5.65 \mathrm{~mm}$. At this time, the maximum principal stress of the bottom surrounding rock remains unchanged, while the intermediate principal stress and the minimum principal stress rotate $90^{\circ}$ in the cross-sectional plane of the roadway. The direction of maximum principal stress of surrounding rock in roadway is consistent with the direction of roadway axis, while the direction of intermediate principal stress is parallel to the contour line of roadway section, and the area near shallow surrounding rock is shear failure.

In the process of roadway excavation, the stress of surrounding rock changes from three directions to two directions, and the stress path is complex. The rotation of the maximum principal stress of the side wall of the roadway is significant, and the changes of the intermediate principal stress and the minimum principal stress are small. To 


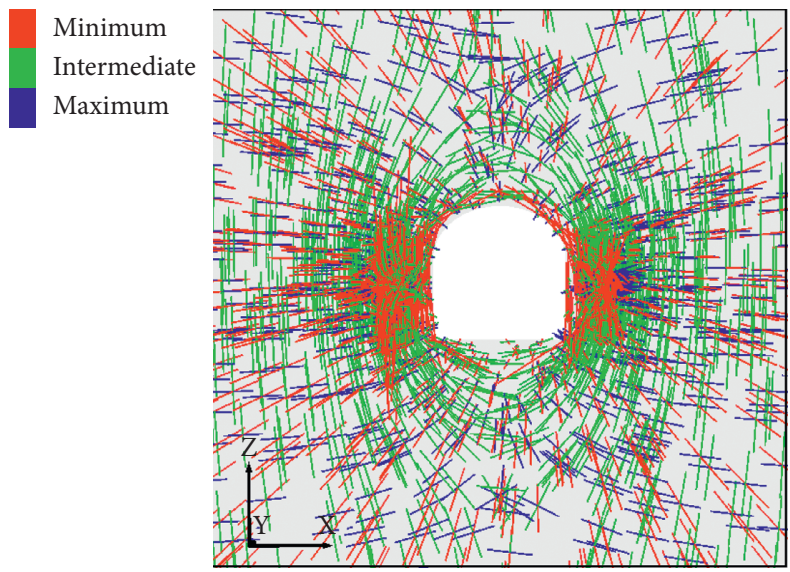

FIGURE 7: Distribution of principal stress in surrounding rock of roadway.
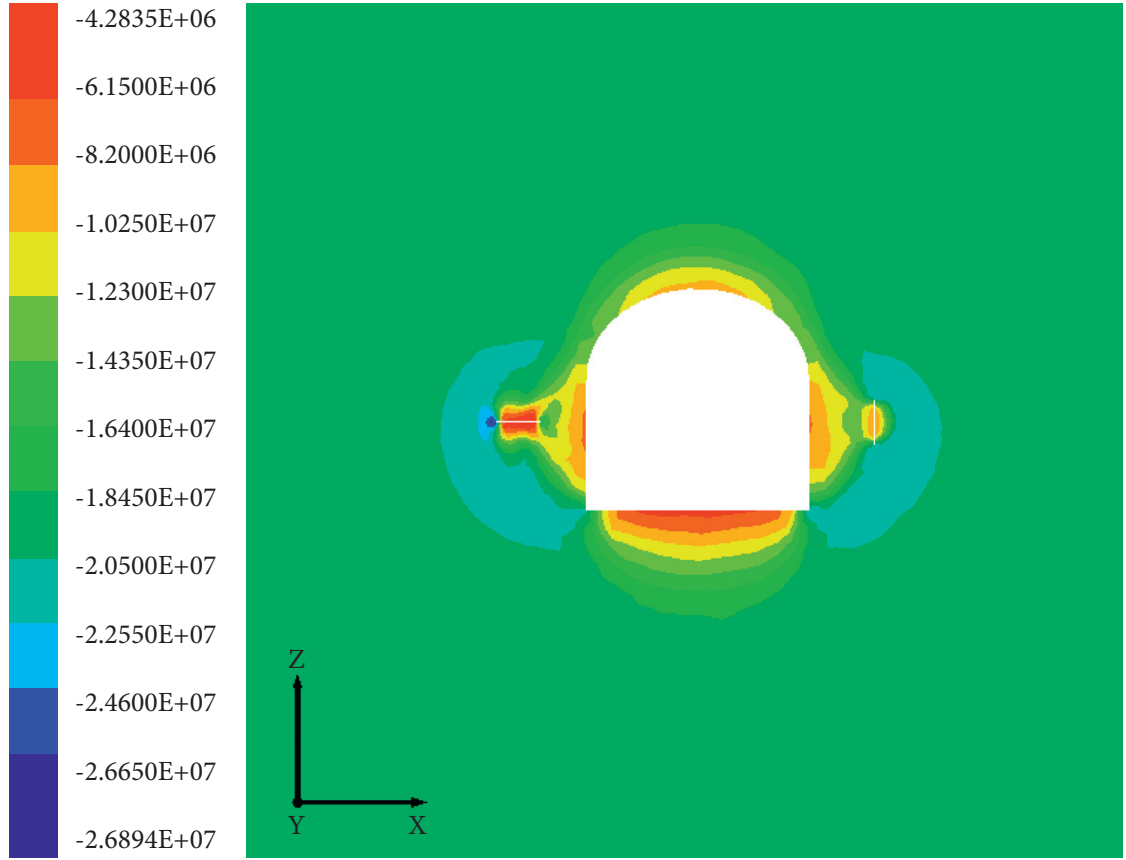

FIGURE 8: Nephogram of maximum principal stress distribution.

simplify the model, the cracks in the left side wall are selected for analysis, and the change path of the principal stress during the excavation of the side wall is shown in Figure 11.

The distribution of shear stress and plastic zone of surrounding rock is shown in Figure 12. In the plane where the cracks at the side wall are located, the maximum principal stress rotates $90^{\circ}$ around the $0 x$ axis, and only I-II composite cracks are considered. When $\beta=90^{\circ}$, the cracks develop in the direction of smaller shear load. Because of the width of the cracks in the model, the plastic zone in the $Z$-axis first appears tensile failure, and then shear failure. With the redistribution of stress, the cracks on the left side wall gradually change into tensile failure mode, and tensile plastic zone appears in the low shear stress area. A tensile stress of $0.9 \mathrm{MPa}$ appears at monitoring point 2 of roadway, and stress intensity factors
$K_{I}=1.59$ and $K_{I I}=0$ are obtained by formula (11). When $\beta=0^{\circ}$, the plastic zone in the $Z$-axis direction of the crack does not develop, and the two sides are distributed as shear plastic zones, while the plastic zone distribution of the right side wall is not affected by the crack, so it is considered to have "directional stability."

\section{Discussion and Analysis}

5.1. Influence of Principal Stress Rotation on Crack Development. Under the unloading conditions during mining excavation, the rock mass often undergoes failures due to compressive shearing and tensile shear, which can be simplified to the I-II composite fracture according to the fracture mechanics theory. In the theory of maximum hoop tensile stress, the crack will expand 


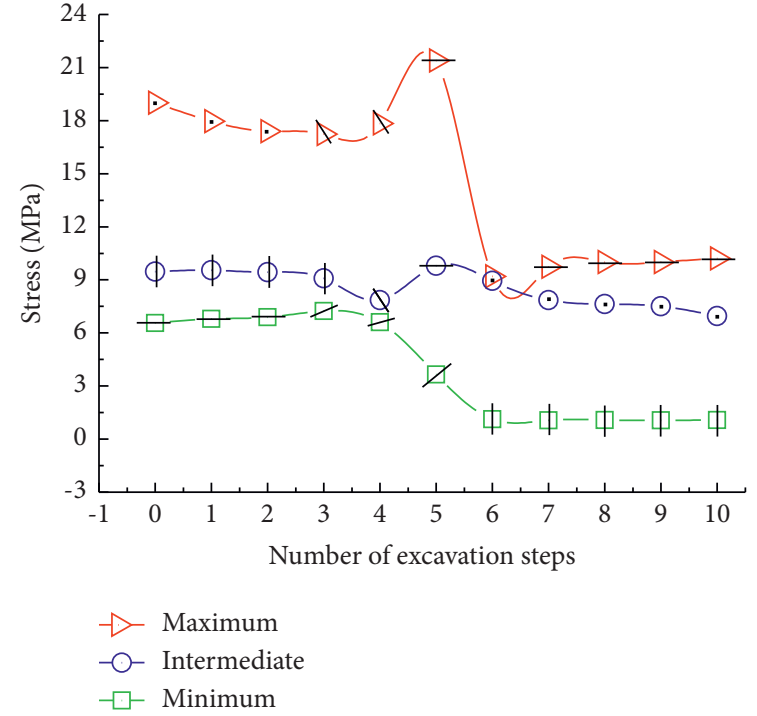

(a)

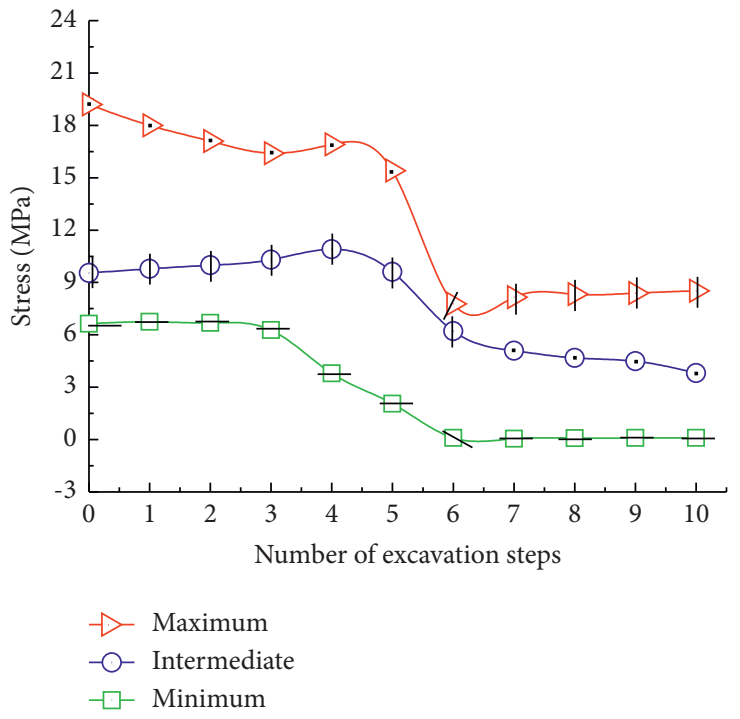

(b)

Figure 9: Principal stress value and direction change curve of monitoring point. (a) Top of tunnel. (b) Tunnel sidewall.

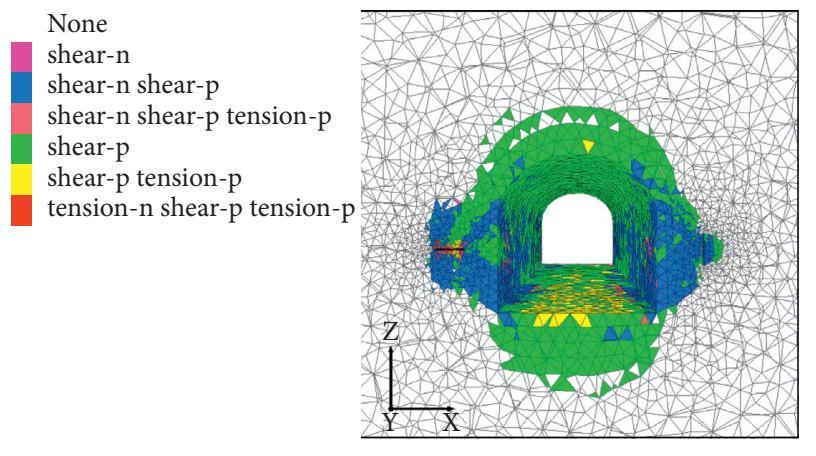

FIGURE 10: Distribution of plastic zone in surrounding rock of roadway.

toward the original fracture surface in some angle direction when the critical value is reached. Under the condition of diagonal tension stress, the fracture angle $\theta_{0}$ of crack growth gradually decreases with the increase of crack angle $\beta$, and the direction of crack growth is consistent with the direction of maximum hoop tension stress. Under the condition of compressive stress, the fracture angle of crack growth increases with the increase of crack angle, and the direction of crack growth is approximately consistent with the direction of maximum compressive stress. Therefore, the further development of crack angle is related to the direction of principal stress. During the rotation of principal stress, the fracture angle is constantly changing, resulting in new cracks.

The crack tends to propagate along its own plane, the research on nonplanar crack propagation shows that the applied shear stress makes the crack deviate from the original plane, and the deviation always occurs from the direction of larger shear stress to the direction of minimum shear stress. According to Mohr-Coulomb strength theory, the D-value between the maximum principal stress and the minimum principal stress in numerical simulation is shear stress, and the failure of rock mass is usually caused by shear failure. Therefore, the plastic zone of surrounding rock in the area with large shear stress is more distributed, and the plastic zone gradually expands from the stress concentration area to the shear stress reduction area, in which the tensile plastic zone is mostly distributed at the crack tip (as shown in Figure 10).

However, the development of cracks in rock mass is very complex, and the three-dimensional evolution law of cracks cannot be obtained by using the simplified uniaxial compression and tension model. Rotation of principal stress is a nonplanar propagation problem. During the excavation of $3 \mathrm{D}$ roadway model, the rotation of principal stress makes the plane of crack change. Because crack propagation tends to propagate along its own plane, the crack starts to keep "directional stability" on the new plane, which eventually leads to the deviation of crack development direction. This model only analyzes the development trend of cracks under rotational stress, and further research is needed for the fracture conditions of cracks in the new stress plane.

5.2. Changes of Stress Field at Crack Tip. During the development of I-II composite fractures, the crack system gradually changes from mixed to pure type I by dredging loads, and the failure model is shown in Figure 2(b). In Figure 5, with the further expansion of the crack, the mode I load is much larger than the mode II load, which indicates that the direction of the defect is an important mechanical parameter affecting the initial crack growth. In addition, the "relative initial angle" of the crack angle is updated in real time during the principal stress rotation and will become the next crack initial angle after each stress rotation. The rotation of stress direction leads to stress concentration and oscillation around the crack tip, 


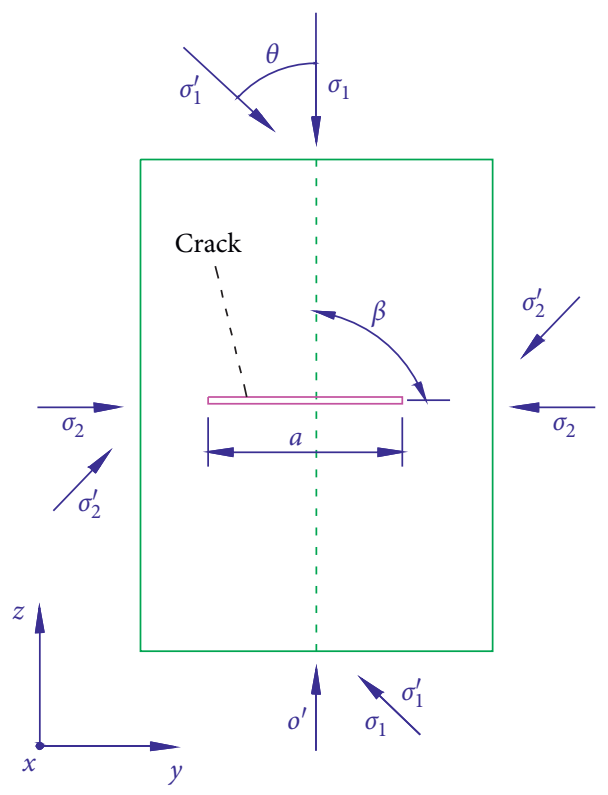

FIGURE 11: Schematic diagram of principal stress change path.

shear- $n$ shear-p tension- $p$ shear-p

shear-p tension-p

tension-n shear-p tension- $\mathrm{p}$

$1.0241 \mathrm{E}+07$

$1.0000 \mathrm{E}+07$

$9.5000 \mathrm{E}+06$

$9.0000 \mathrm{E}+06$

$8.5000 \mathrm{E}+06$

$8.0000 \mathrm{E}+06$

$7.5000 \mathrm{E}+06$

$7.0000 \mathrm{E}+06$

$6.5000 \mathrm{E}+06$

$6.0000 \mathrm{E}+06$

$5.5000 \mathrm{E}+06$

$5.0000 \mathrm{E}+06$

$4.5000 \mathrm{E}+06$

$4.0000 \mathrm{E}+06$

$3.5000 \mathrm{E}+06$

$3.0000 \mathrm{E}+06$

$2.5929 \mathrm{E}+06$

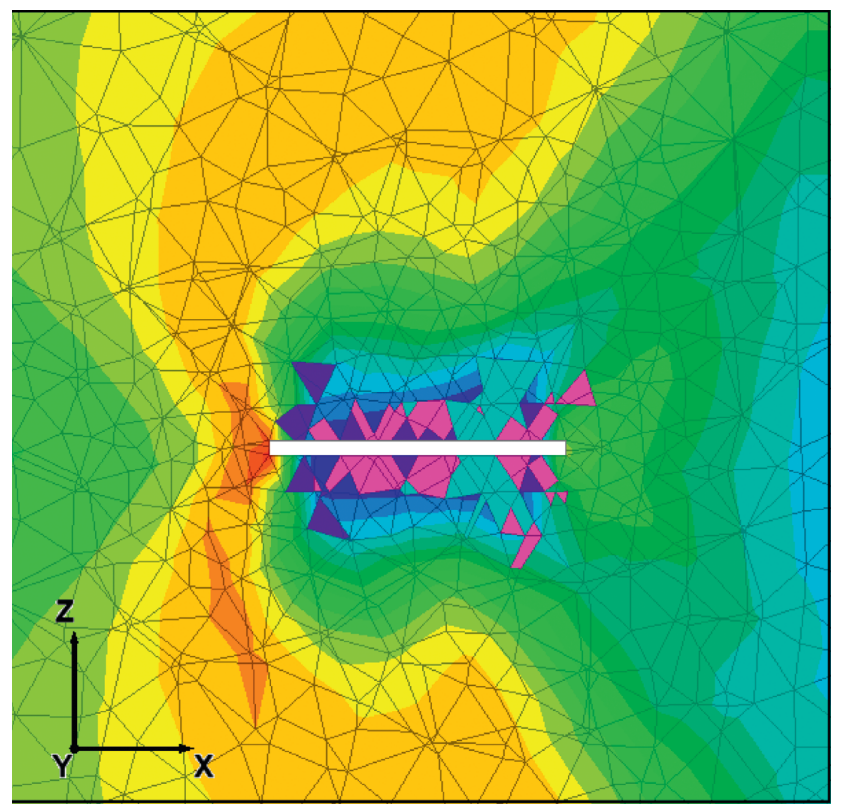

(a)

Figure 12: Continued. 


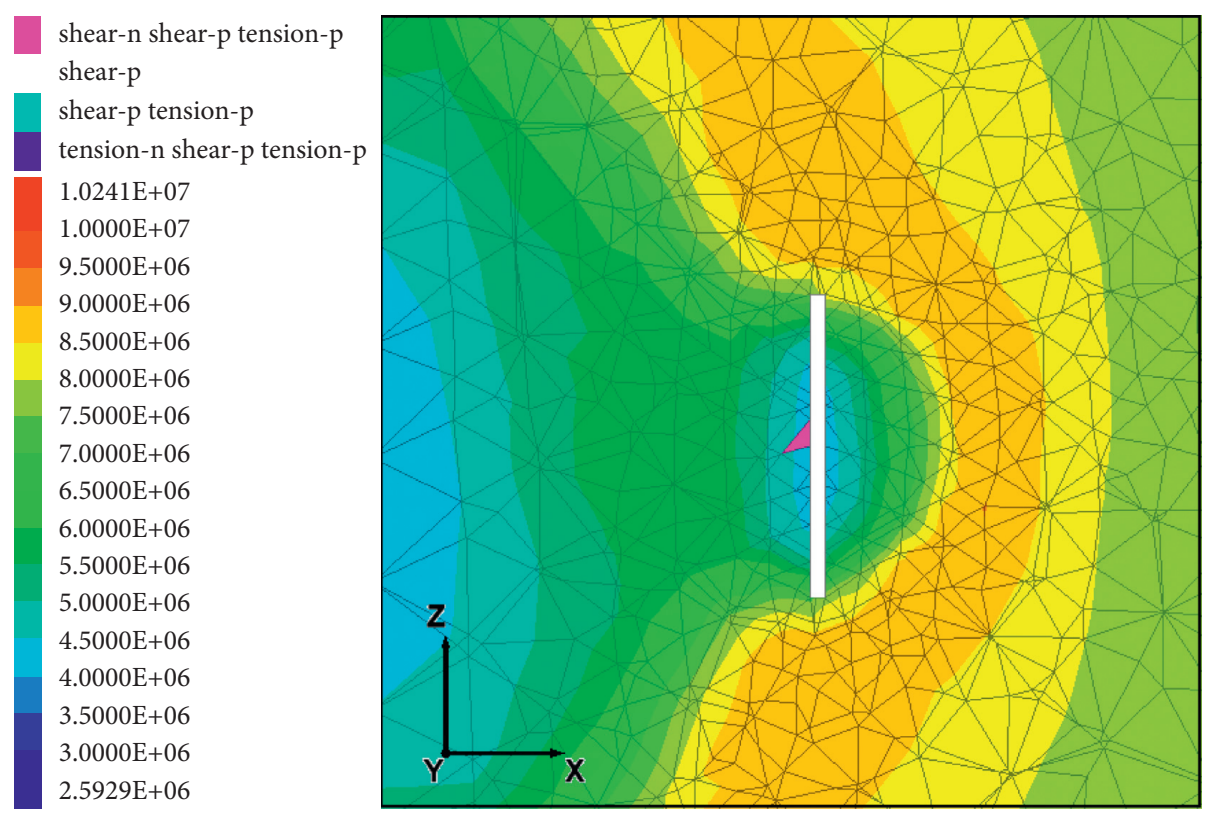

(b)

FIGURE 12: Shear stress and plastic zone distribution of surrounding rock. (a) Contour of maximum shear stress in horizontal direction. (b) Contour of maximum shear stress in vertical direction.

which promotes the development of cracks to microcracks scattered around. The secondary fracture originated from the front of the expanding crack tip and developed backward to connect with the main crack tip, which showed a certain "attractive force."

The rotation of the principal stress causes the deviation of the crack development direction, which is not conducive to accelerate the expansion of the initial crack on the smooth surface, and inhibits the depth of the crack in the initial direction to a certain extent. However, the principal stress rotation can cause the surrounding rock damage accumulation and accelerate the front of the main crack to form and develop into separate entities. In Figure 10, the principal stress directions of the surrounding rock surfaces of the tunnel rotate most strongly (the maximum principal stress direction is no longer the axis direction of the tunnel), which increases the degree of fracture of the surrounding rock on the tunnel surfaces.

\section{Conclusion}

(1) The relative initial angle of the crack angle is updated in time during the principal stress rotation process. Once the stress is rotated, it will become the next initial crack angle. In the nonplanar crack propagation, the crack deviates under the applied shear load. The direction of crack is always toward the direction of the minimum shear load. The depth of crack in the initial direction is inhibited to a certain extent, but the principal stress rotation causes the accumulation of surrounding rock damage.

(2) According to the results of numerical simulation, it can be seen that the effect of principal stress rotation caused by mining excavation is obvious and has a certain range of influence depth, the stress of surrounding rock of roadway is the highest within the depth range of $1 \sim 2 \mathrm{~m}$, the maximum principal stress is as high as $26.89 \mathrm{MPa}$, and the area with small excavation shear stress is the direction of further development of cracks. The rotation of principal stress direction on the roadway surrounding rock surface is the strongest, which makes the surrounding rock more fragmented, and the middle principal stress and the maximum principal stress rotate about $90^{\circ}$ counterclockwise along the $O x$ axis.

(3) The initiation and development direction of plane cracks and nonplane cracks under stress rotation are discussed in this paper, but it is difficult to reproduce the complex stress path of engineering rock mass excavation with simplified model. In the follow-up work, it is necessary to build a model from the principal stress rotation path, study the rock mass variation characteristics when the principal stress axis rotates continuously, and establish the stress-strain relationship of rock mass under the action of principal stress axis rotation.

\section{Data Availability}

The data used in the field measurement can be obtained from the corresponding author upon request.

\section{Conflicts of Interest}

The authors declare no potential conflicts of interest with respect to the research, authorship, and/or publication of this article. 


\section{Acknowledgments}

The authors acknowledge the financial support for this work provided by the National Natural Science Foundation of China (grant no. 51774010).

\section{References}

[1] T. Qin, H. Sun, H. Liu et al., "Experimental study on mechanical and acoustic emission characteristics of rock samples under different stress paths," Shock and Vibration, vol. 2018, Article ID 4813724, 9 pages, 2018.

[2] H. P. Xie, F. Gao, and Y. Ju, "Research and development of rock mechanics in deep ground engineering," Chinese Journal of Rock Mechanics and Engineering, vol. 34, no. 11, pp. 2161-2178, 2015.

[3] H. Wu, D. Ma, S. Spearing et al., "Fracture phenomena and mechanisms of brittle rock with different numbers of openings under uniaxial loading," Geomechanics and Engineering, vol. 25, no. 6, pp. 481-493, 2021.

[4] M. Moghaddam, M. Ayatollahi, and F. Berto, "Mixed mode fracture analysis using generalized averaged strain energy density criterion for linear elastic material," International Journal of Solids and Structures, vol. 120, pp. 135-145, 2017.

[5] X. P. Zhou, J. Z. Zhang, and F. Berto, "Fracture analysis in brittle sandstone by digital imaging and AE techniques: role of flaw length ratio," Journal of Materials in Civil Engineering, vol. 32, no. 5, 2020 .

[6] D. Wan, Z. Zhu, C. Zhou, J. Li, P. Ying, and M. Wang, "Effect of pre-existing symmetrical cracks on propagation behaviors of a blast-induced crack," Shock and Vibration, vol. 2020, Article ID 5892324, 16 pages, 2020.

[7] Q. Ma, Y. L. Tan, X. S. Liu, Q. Gu, and X. Li, "Effect of coal thicknesses on energy evolution characteristics of roof rockcoal-floor rock sandwich composite structure and its damage constitutive model," Composites Part B: Engineering, vol. 198, no. 1, Article ID 108086, 2020.

[8] J.-Z. Zhang, X.-P. Zhou, and P. Yin, "Visco-plastic deformation analysis of rock tunnels based on fractional derivatives," Tunnelling and Underground Space Technology, vol. 85, pp. 209-219, 2019.

[9] L. L. Gu, Z. Wang, Q. Huang, G. Ye, and F. Zhang, "Numerical investigate into ground treatment to mitigate the permanent train-induced deformation of pile-raft-soft soil system," Transportation Geotechnics, vol. 24, Article ID 100368, 2020.

[10] X. Z. Li and C. Z. Qi, "Study on microcrack growth-based dynamic compressive mechanical properties in brittle rocks," Explosion and Shock Waves, vol. 39, no. 8, pp. 52-62, 2019.

[11] D. Y. Li, Z. Y. Han, X. L. Sun, and X. Li, "Characteristics of dynamic failure of marble with artificial flaws under split Hopkinson pressure bar tests," Chinese Journal of Rock Mechanics and Engineering, vol. 36, no. 12, pp. 2872-2883, 2017.

[12] B. Sun, S. Liu, S. Zeng et al., "Dynamic characteristics and fractal representations of crack propagation of rock with different fissures under multiple impact loadings," Scientific Reports, vol. 11, no. 1, 2021.

[13] C. Pan, X. Li, L. He, and J. Li, "Study on the effect of microgeometric heterogeneity on mechanical properties of brittle rock using a grain-based discrete element method coupling with the cohesive zone model," International Journal of Rock Mechanics and Mining Sciences, vol. 140, Article ID 104680, 2021.

[14] J. W. Fu, W. S. Zhu, L. G. Wang, and X. G. Wang, "Numerical simulation of the crack propagation processes in rocks with double Joints," Applied Mechanics and Materials, vol. 90-93, pp. 559-564, 2011.

[15] Z. H. Shang, L. Guo, and Q. L. Zhu, "Statistical laws for stress and strain under uniaxial compression test based on FLAC3D," Journal of Hunan University of Science and Technology (Natural Science Edition), vol. 35, no. 2, pp. 18-26, 2020.

[16] G. T. Meng, S. H. He, J. L. Chen et al., "Mechanism of deep deformation of roof arch of underground powerhouse at right bank of Baihetan Hydropower Station," Chinese Journal of Geotechnical Engineering, vol. 42, no. 3, pp. 576-587, 2020.

[17] X. Wang, N. Wu, H. Li, and Y. Yan, "Influence of joint angle on the instability failure characteristics and AE evolution law of underground caverns," European Journal of Environmental and Civil Engineering, 2020.

[18] X. P. Zhou, Y. J. Lian, L. N. Y. Wong, and F. Berto, "Understanding the fracture behavior of brittle and ductile multi-flawed rocks by uniaxial loading by digital image correlation," Engineering Fracture Mechanics, vol. 199, pp. 438-460, 2018.

[19] S. Liu, D. Zhang, and H. Liu, "Rock crack propagation mechanism of oriented perforation hydraulic fracture under different perforation parameters," Arabian Journal for Science and Engineering, vol. 45, no. 10, pp. 8711-8725, 2020.

[20] J. C. Wang, Z. H. Wang, J. Yang et al., "Mining-induced stress rotation and its application in longwall facewith large length in kilometer deep coal mine," Journal of China Coal Society, vol. 45, no. 3, pp. 876-888, 2020.

[21] H. Wu, B. Dai, L. Cheng, R. Lu, G. Zhao, and W. Liang, "Experimental study of dynamic mechanical response and energy dissipation of rock having a circular opening under impact loading," Mining, Metallurgy \& Exploration, vol. 38, no. 2, pp. 1111-1124, 2021.

[22] J. H. Li, Q. Shen, Z. Q. Zhu et al., "Analysis of stress path and failure mode of surrounding rock during Mine-by test tunnel excavation," Chinese Journal of Rock Mechanics and Engineering, vol. 36, no. 4, pp. 821-830, 2017.

[23] E. Hoek, C. D. Martin, W. Vancouver et al., "Fracture initiation and propagation in intact rock-a review," Journal of Rock Mechanics and Geotechnical Engineering, vol. 6, no. 4, pp. 287-300, 2014.

[24] X.-P. Zhou, Y.-X. Zhang, Q.-L. Ha, and K.-S. Zhu, "Micromechanical modelling of the complete stress-strain relationship for crack weakened rock subjected to compressive loading," Rock Mechanics and Rock Engineering, vol. 41, no. 5, pp. 747-769, 2008.

[25] F. Erdogan and G. C. Sih, "On the crack extension in plates under plane loading and transverse shear," Journal of Basic Engineering, vol. 85, no. 4, pp. 519-525, 1963.

[26] B. Cotterell and J. R. Rice, "Slightly curved or kinked cracks," International Journal of Fracture, vol. 16, no. 2, pp. 155-169, 1980.

[27] M. Gell and E. Smith, "The propagation of crack through grain boundaries in polycrystalline $3 \%$ silicon-iron," Acra Metall.vol. 15, no. 2, pp. 253-258, 1967.

[28] D. M. Wan, Z. Y. Zhu, R. F. Liu et al., "Study of propagation behaviors of mode I cracks under blasting stress wave based on RPC specimens," Chinese Journal of Rock Mechanics and Engineering, vol. 38, no. 12, pp. 2478-2490, 2019.

[29] H. J. Wang, H. Z. Li, and R. Ren, "Three-point bending test study on the propagation law of internal cracks and failure characteristics of brittle solids based on 3D-ILC technology," Chinese Journal of Rock Mechanics and Engineering, vol. 38, no. 12, pp. 2463-2477, 2019. 